05.3

\title{
Фазовый переход полупроводник-металл и „тристабильное“ электрическое переключение в нанокристаллических пленках оксида ванадия на кремнии
}

\author{
(C) Е.А. Тутов ${ }^{1}$, Д.Л. Голощапов ${ }^{2}$, В.П. Зломанов ${ }^{3}$ \\ ${ }^{1}$ Воронежский государственный технический университет, Воронеж, Россия \\ ${ }^{2}$ Воронежский государственный университет, Воронеж, Россия \\ ${ }^{3}$ Московский государственный университет им. М.В. Ломоносова, Москва, Россия \\ E-mail: tutov_ea@mail.ru
}

Поступило в Редакцию 18 марта 2019 г.

В окончательной редакции 21 марта 2019г.

Принято к публикации 22 марта 2019г.

По измерениям на переменном токе температурной зависимости проводимости нанокристаллических пленок смешанного оксида ванадия на кремнии обнаружена многоступенчатая форма петли гистерезиса при фазовом переходе полупроводник-металл в $\mathrm{VO}_{2}$. При измерениях на постоянном токе сложная форма петли гистерезиса не проявляется. Такие особенности связаны с размерным эффектом и гетерофазностью пленки оксида ванадия, а также с различным типом носителей заряда в объеме нанокристаллитов и на их поверхностях. Появление ступенек объясняется фазовым переходом в отдельных группах кристаллитов близкого размера. В таких пленках впервые наблюдается „тристабильное“ электрическое переключение.

Ключевые слова: оксид ванадия, нанокристаллические пленки, фазовый переход полупроводник-металл, электрическое переключение.

DOI: 10.21883/PJTF.2019.12.47907.17788

Фазовый переход первого рода полупроводник-металл в диоксиде ванадия с неубывающим интересом интенсивно исследуется в течение шестидесяти лет, в последнее десятилетие в связи с разнообразными возможностями его практического применения в сверхбыстрой электронике [1], мемристорах [2], осцилляторных нейронных сетях на основе бистабильных элементов, использующих эффекты электрического переключения в $\mathrm{VO}_{2}$-структурах [3]. Новые направления разработки логических элементов и типов мемристорных устройств требуют поиска материалов и структур, имеющих три стабильных состояния [4].

Известно, что фазовый переход полупроводник-металл в керамическом и пленочном диоксиде ванадия представляет собой перколяционный процесс. Наблюдаемая в экспериментах по проводимости петля термического гистерезиса отражает процесс образования бесконечного проводящего кластера вблизи перколяционного порога [5,6]. Фактически происходит переход полупроводник-металл в каждом кристаллите и перколяционный переход по всей совокупности кристаллитов в целом [7]. Поэтому при измерениях проводимости на переменном токе термическое положение порога протекания может зависеть от частоты измерительного сигнала.

В работах $[8,9]$, посвященных уточнению особенностей механизма проводимости пленочного диоксида ванадия, на основании измерения частотной зависимости проводимости и ее температурной зависимости на постоянном и переменном токе в температурной области вблизи фазового перехода делается заключение, что в перколяционный переход в диоксиде ванадия вносят вклад как носители заряда, локализованные на дефектных центрах, так и делокализованные (зонные) носители заряда. Поэтому при температурах вблизи фазового перехода в диоксиде ванадия, по-видимому, имеет место смешанный механизм проводимости. Как было показано теоретически и экспериментально на основании оптических исследований [10-12], петля термического гистерезиса в нанокристаллических пленках диоксида ванадия при фазовом переходе может иметь асимметричную многоступенчатую форму.

В настоящей работе исследованы особенности фазового перехода в нанокристаллических пленках смешанного оксида ванадия и эффекта электрического переключения в структурах на его основе.

В соответствии с методикой работы [13] пленки оксида ванадия синтезировали из $0.5 \mathrm{M}$ раствоpa триэтоксиванадила $\mathrm{VO}(\mathrm{OEt})_{3}$ в метилцеллозольве $\mathrm{CH}_{3} \mathrm{OCH}_{2} \mathrm{CH}_{2} \mathrm{OH}$, нанося его методом центрифугирования на подложку монокристаллического кремния ориентации (001). При этом происходил гидролиз этоксида ванадила и образовывался слой аморфных оксо- и гидроксополимеров. После этого образец подвергался ИК-сушке для испарения избытка растворителя. Затем образец отжигался в муфельной печи на воздухе при $500^{\circ} \mathrm{C}$ для образования пентаоксида ванадия. Далее проводился восстановительный отжиг в токе смеси $5 \% \mathrm{H}_{2}+95 \% \mathrm{Ar}$ при $450^{\circ} \mathrm{C}(10-30 \mathrm{~min})$.

Фазовый анализ образцов осуществлялся на рентгеновском дифрактометре ДРОН-4.0 при отфильтрованном $K_{\alpha}$-излучении кобальта со средневзвешенной 
длиной волны $\lambda=0.179021 \mathrm{~nm}$ при режиме трубки $30 \mathrm{kV}, 20 \mathrm{~mA}$. Средний размер кристаллитов определялся по уширению рефлексов рентгеновской дифракции по соотношению Дебая-Шерера. Электрофизические характеристики структур $\mathrm{Ag} / \mathrm{VO}_{x} / \mathrm{Si}$ изучались методом импедансной спектроскопии в диапазоне частот $12 \mathrm{~Hz}-100 \mathrm{kHz}$ (на приборе LCR-meter GW Insteck LCR-819). Измерения проводились в интервале температур от 20 до $100^{\circ} \mathrm{C}$. Скорость нагревания и охлаждения составляла примерно один градус в минуту.

В качестве объекта исследований также был использован коммерческий терморезистор (ТР-68) на основе пленки диоксида ванадия.

Восстановительный отжиг пленок высшего оксида ванадия на кремнии в течение $30 \mathrm{~min}$ привел к появлению на дифрактограмме рефлексов фаз оксидов $\mathrm{VO}_{2}$, $\mathrm{V}_{2} \mathrm{O}_{5}$ и $\mathrm{V}_{6} \mathrm{O}_{13}$ с размером кристаллитов $15-100 \mathrm{~nm}$ (см. таблицу). Фаза диоксида ванадия идентифицирована нами как метастабильная полиморфная модификация, обычно обозначаемая как $\mathrm{VO}_{2}(\mathrm{~B})$. Для фаз $\mathrm{V}_{6} \mathrm{O}_{13}$ и
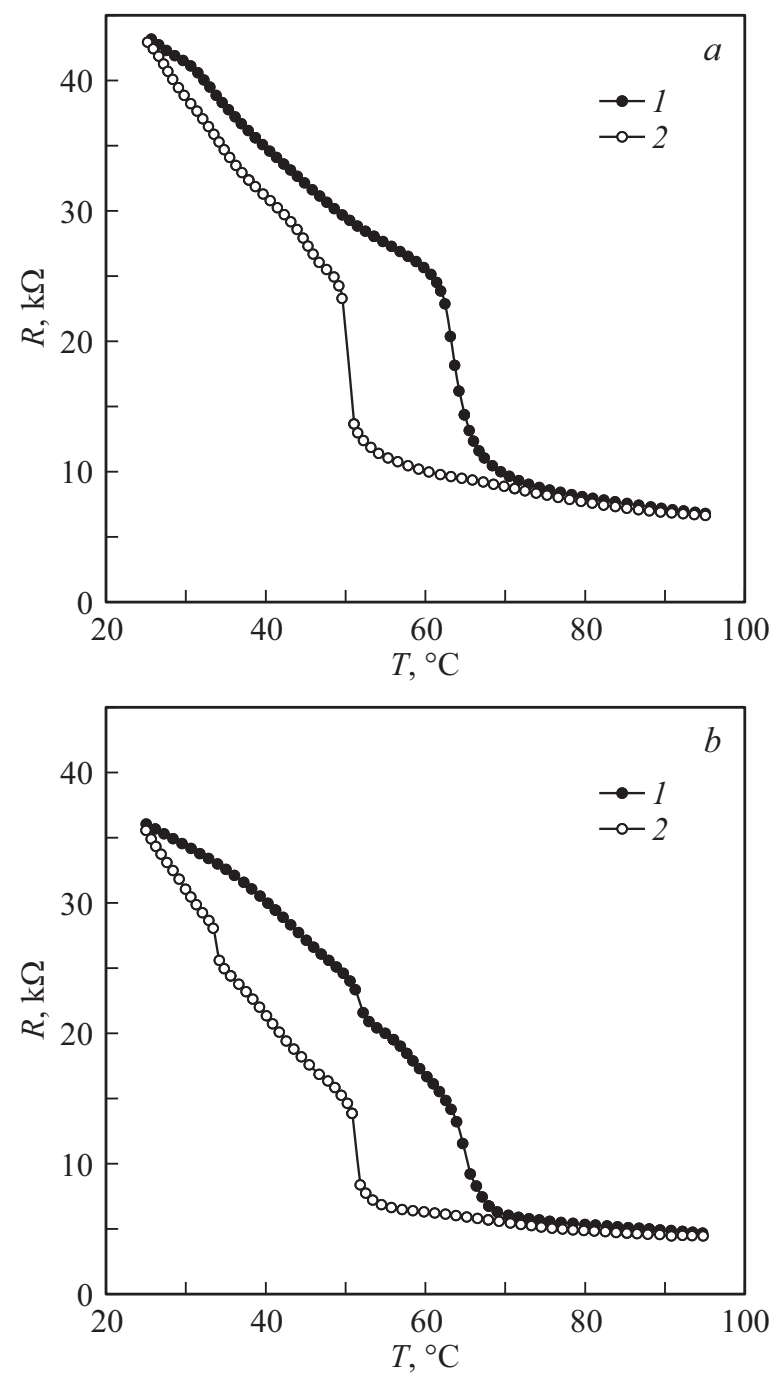

Рис. 1. Температурная зависимость сопротивления структуры $\mathrm{Ag} / \mathrm{VO}_{x} / \mathrm{Si} . a-$ постоянный ток, $b-$ переменный ток, частота $1 \mathrm{kHz} .1$ - нагревание, 2 - охлаждение.
Дифрактометрический анализ пленки оксида ванадия на кремнии после восстановительного отжига в течение $30 \mathrm{~min}$ (средний размер кристаллитов диоксида ванадия $25 \mathrm{~nm}$ )

\begin{tabular}{c|c|c|c|c|c}
\hline $\begin{array}{c}\text { Номер } \\
\text { рефлекса }\end{array}$ & $\begin{array}{c}\text { Угол, } \\
\text { deg }\end{array}$ & $\begin{array}{c}\text { Относительная } \\
\text { интенсивность }\end{array}$ & $d, \mathrm{~nm}$ & $(h k l)$ & Фаза \\
\hline 1 & 10.40 & 32.12 & 0.988 & $(001)$ & $\mathrm{V}_{6} \mathrm{O}_{13}$ \\
2 & 16.70 & 9.27 & 0.616 & $(001)$ & $\mathrm{VO}_{2}(\mathrm{~B})$ \\
3 & 20.70 & 29.47 & 0.498 & $(002)$ & $\mathrm{V}_{6} \mathrm{O}_{13}$ \\
4 & 23.60 & 19.00 & 0.438 & $(001)$ & $\mathrm{V}_{2} \mathrm{O}_{5}$ \\
5 & 31.30 & 100.00 & 0.332 & $(003)$ & $\mathrm{V}_{6} \mathrm{O}_{13}$ \\
6 & 33.90 & 41.06 & 0.307 & $(002)$ & $\mathrm{VO}_{2}(\mathrm{~B})$ \\
7 & 38.50 & 78.48 & 0.272 & $(002)$ & $c-\mathrm{Si}_{1}$ \\
8 & 42.20 & 15.89 & 0.249 & $(004)$ & $\mathrm{V}_{6} \mathrm{O}_{13}$ \\
9 & 48.50 & 21.85 & 0.218 & $(002)$ & $\mathrm{V}_{2} \mathrm{O}_{5}$ \\
10 & 52.00 & 14.90 & 0.204 & $(003)$ & $\mathrm{VO}_{2}(\mathrm{~B})$ \\
11 & 53.40 & 24.83 & 0.200 & $(005)$ & $\mathrm{V}_{6} \mathrm{O}_{13}$
\end{tabular}

$\mathrm{VO}_{2}(\mathrm{~B})$ наблюдаются рефлексы только от плоскостей с индексами $(00 l)$.

Для структуры с гетерофазной пленкой оксида ванадия, содержащей фазу $\mathrm{VO}_{2}(\mathrm{~B})$, при исследовании температурной зависимости сопротивления на постоянном и переменном токе различной частоты наблюдались характерные для фазового перехода ступенчатое изменение проводимости и петля гистерезиса в интервале температур $50-70^{\circ} \mathrm{C}$ (рис. $\left.1, a, b\right)$. Суммарное изменение сопротивления структуры при фазовом переходе в диоксиде ванадия не слишком значительное, что связано с протеканием тока по другим полупроводниковым фазам. Обращают на себя внимание многоступенчатый вид петли гистерезиса при измерении на переменном токе и ее несимметричная форма. При измерениях на постоянном токе сложная форма петли гистерезиса не проявляется.

Такие особенности связывают с размерным эффектом при фазовом переходе полупроводник-металл в нанокристаллических композитных пленках диоксида ванадия [12]. Причина образования широкой петли гистерезиса состоит в наличии в пленке большого числа нанокристаллитов различных размеров, каждый из которых обладает собственной „элементарной“ петлей гистерезиса, так что результирующая петля формируется суммированием элементарных петель, присущих отдельным зернам оксида. Появление ступенек связано с фазовым переходом в отдельных группах кристаллитов близкого размера.

Вольт-амперные характеристики (ВАХ) структур $\mathrm{Ag} / \mathrm{VO}_{x} / \mathrm{Si}$ с такими пленками изучались с помощью характериографа и фиксировались на цифровую камеру. Они отличаются сложным видом (рис. 2) с электрическим переключением при положительном смещении. Структура $\mathrm{Ag} / \mathrm{VO}_{x} / \mathrm{Si}$ имеет несимметричную $\mathrm{BAX}$ диодного типа с существенно различающимися токами в пропускном и запирающем направлениях. Поскольку использовалась кремниевая подложка $n$-типа проводимости, прямому смещению соответствует положительная 
полярность приложенного напряжения на Ag-электроде. При отрицательной полярности напряжения на этом электроде (обратное смещение) последовательно к сопротивлению слоя $\mathrm{VO}_{x}$ добавляется значительное сопротивление обедненного подвижными электронами слоя области пространственного заряда в кремнии, ограничивающее сквозной ток через структуру. При этом диоксид ванадия не разогревается до температуры фазового перехода, и электрического переключения не наблюдается.

При напряжении около $2 \mathrm{~V}$ структура может находиться в трех стабильных состояниях, разделенных областями с отрицательным дифференциальным сопротивлением. Такое поведение может быть связано с гетерофазностью нанокристаллической пленки оксида ванадия, а также с различным типом носителей заряда в объеме нанокристаллитов и на их поверхностях [8].

Для терморезистора ТР-68 при измерениях на постоянном токе фазовый переход в пленке диоксида

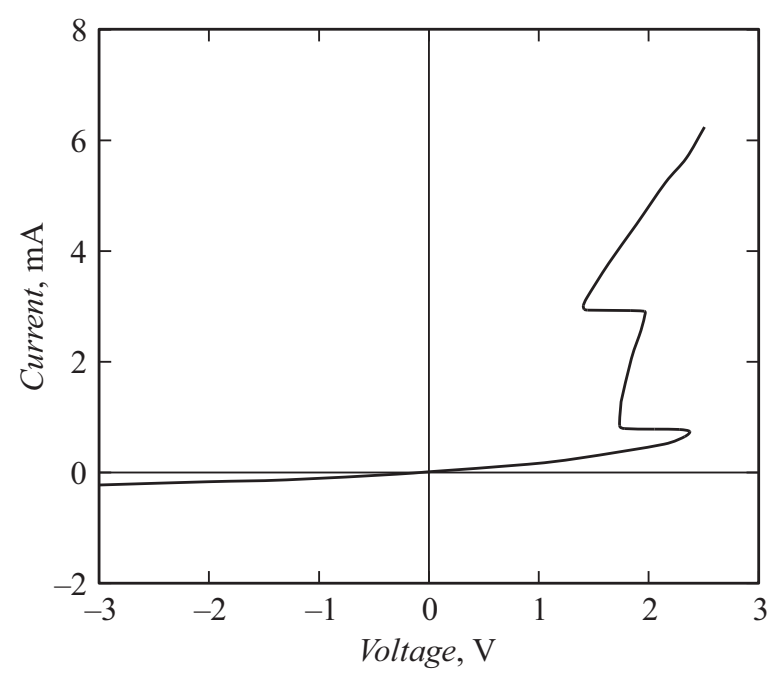

Рис. 2. Вольт-амперная характеристика (осциллограмма) структуры $\mathrm{Ag} / \mathrm{VO}_{x} / \mathrm{Si}$. Полярность напряжения указана для $\mathrm{Ag}$-электрода.

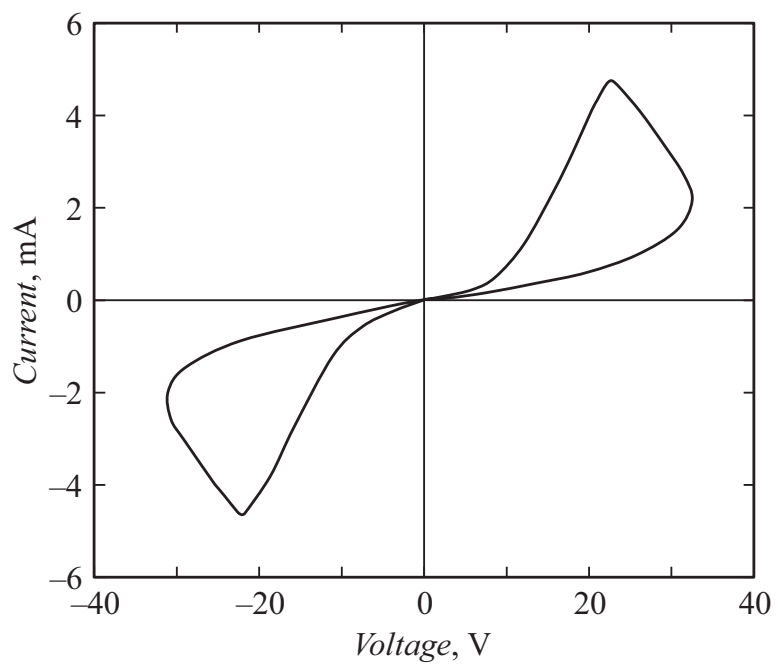

Рис. 3. Вольт-амперная характеристика (осциллограмма) терморезистора ТР-68. ванадия происходит с изменением сопротивления примерно на четыре порядка и занимает температурный интервал около десяти градусов, при измерениях на переменном токе петля гистерезиса расширяется на несколько градусов и смещается в сторону более высоких температур, причем нагревательная ветвь смещена более значительно, чем охладительная [8]. ВАХ терморезистора (рис. 3) также демонстрируют электрическое переключение, вызванное саморазогревом под действием протекающего тока до температуры фазового перехода. Этот эффект является предметом интенсивных исследований для квазиодномерных нанопроволок диоксида ванадия, для которых энергетические затраты на переключение минимальны [14].

Таким образом, трапециевидная ступенчатая форма петли термического гистерезиса, обнаруженная по измерениям проводимости на переменном токе, объясняется последовательным фазовым переходом в группах нанокристаллитов диоксида ванадия близкого размера. При измерениях на постоянном токе сложная форма петли гистерезиса не проявляется. В структурах с такими пленками обнаруженное „тристабильное“ электрическое переключение наблюдается впервые.

\section{Конфликт интересов}

Авторы заявляют, что у них нет конфликта интересов.

\section{Список литературы}

[1] Yang Z., Ko C., Ramanathan S. // Annu. Rev. Mater. Res. 2011. V. 41. P. 337-367.

[2] Pershin Y.V., Di Ventra M. // Adv. Phys. 2011. V. 60. N 2. P. 145-227.

[3] Величко А.А., Беляев М.А. // Письма в ЖТФ. 2019. Т. 45. B. 3. C. 3-6.

[4] Mannan Z.I., Yang C., Kim H. // IEEE Circuits Systems Mag. 2018. V. 18. N 2. P. 14-27.

[5] Gentle A.R., Smith G.B., Maaroof A.I. // J. Nanophoton. 2009. V. 3. P. 031505 (1-15).

[6] Gurvitch M., Luryi S., Polyakov A., Shabalov A. // IEEE Transact. Nanotechnol. 2010. V. 9. N 5. P. 647-652.

[7] Ильинский А.В., Квашенкина О.Е., Шадрин Е.Б. // ФТП. 2012. T. 46. B. 9. C. $1194-1208$.

[8] Tutov E.A., Al-Khafaji H.I., Zlomanov V.P. // Smart Nanocomposites. 2017. V. 8. P. 91-99.

[9] Тутов E.A., Мананников A.B., Al-Khafaji H.I., Зломанов В.П. // ЖТФ. 2017. Т. 87. В. 3. С. 367-371.

[10] Golubev V.G., Davydov V.Yu., Kartenko N.F., Kurdyukov D.A., Medvedev A.V., Pevtsov A.B., Scherbakov A.V., Shadrin E.B. // Appl. Phys. Lett. 2001. V. 79. N 14. P. 2127-2129.

[11] Алиев Р.А., Андреев В.Н., Капралова В.М., Климов В.А., Соболев А.И., Шадрин Е.Б. // ФТТ. 2006. Т. 48. В. 5. С. 874 879.

[12] Шадрин Е.Б., Ильинский А.В., Сидоров А.И., Ханин С.Д. // ФTT. 2010. T. 52. В. 11. С. 2269-2276.

[13] Тутов Е.А., Виниченко Д.А., Тутов Е.Е., АльКафаджи Х.И., Румянцева Н.А., Зломанов В.П. // Конденсированные среды и межфазные границы. 2011. Т. 13. № 3. C. 358-362.

[14] Byon J.W., Kim M.B., Kim M.H., Kim S.Y., Lee S.H., Lee B.C., Baik J.M. // J. Phys. Chem. C. 2012. V. 116. N 1. P. 226-230. 